\title{
Product Development Integration Techniques and System Based on CAx and Knowledge Management
}

\author{
doi:10.3991/ijoe.v9iS4.2584 \\ Yongdang Chen, Zhiqiang Bao, Huijuan Ren, Huali Ma and Guangmei Liu \\ Xi'an Polytechnic University, Xi’an, China
}

\begin{abstract}
Knowledge has become a key economic resource of enterprise and to become even only source of competitive advantage. With the structure of the product more and more complicated, function more and more incline to integration and compounding, modern product design is one base on knowledge. Knowledge-based integrated information system, to support knowledge management and technology innovation, is the development trends of information integration system. The integration information of computer aided technology (CAx) was analysed. A data structure of integration product model base on relation database was introduced. Knowledge-based integration system for product development was drawn out. It is a system base on product data management system and knowledge management system. This system framework used synthetically information technology and advanced manufacture technique, and realized product speedy and innovation design.
\end{abstract}

Index Terms-knowledge management, computer aided technology, product development, integration technique

\section{INTRODUCTION}

With the structure of the product more and more complicated, function more and more incline to integration and compounding, new product development need more knowledge. Especially in the face of the fierce competition in the international market, product design and development activities need put more new knowledge into the product in the time. Success of product development depends on the necessary knowledge, especially the content of new knowledge [1-3]. Knowledge-based integrated information system, to support knowledge management and technology innovation, is the development trends of information integration system [4-6].

At present, most enterprises have implemented CAx system, such as CAD, CAPP, CAE, etc. The technique of integration product development based on the PDM and concurrent engineering is put in practice [7-9]. However, these integrated systems for product development don't think the integration of knowledge, and lack the support of knowledge management system [10,11].

Based on the analysis on CAx integrated information, the paper study a data structure of integration product model based on the relational database. Then, a knowledge-based product development integrated framework based on the product data management system and the knowledge management system is puts forward.
This system framework used synthetically information technology and advanced manufacture technique, and realized product speedy and innovation design.

\section{CAX SYSTEM INTEGRATED INFORMATION ANALYSIS}

In the product development process, CAx subsystems generate the main material information of product components part. It indicates the physical properties of the components part, such as component parts id, name, weight, unit, drawing No., etc. At the same time, CAx subsystems also generate the bill of material (BOM) of product design, and the process route, working procedure, etc. For any specific parts and components and the whole, they all have corresponding some common attributes of CAD/CAPP/CAE model. A new CAD/CAPP/CAE model entity can be abstracted. The parts and components and the whole product can inherit all of its attributes. Thus, each subsystem data of CAD/CAE/CAPP can be integrated, and formed a whole data model, as shown in figure 1.

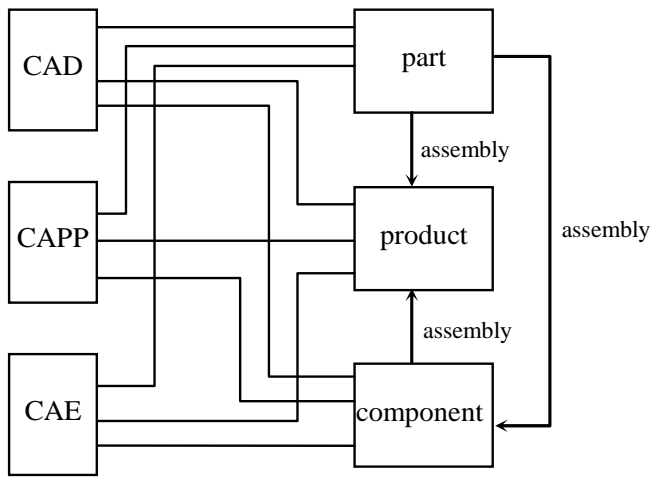

Figure 1. CAx data integration view

\section{A. CAx integrated information description}

As the integrated platform and integrated framework, CAx integrated system manage all relevant information (including the electronic document, graphics files, CAx files, product structure, etc) and all relevant process (including general workflow, engineering change process) of enterprise and products. How to efficiently organize and search this information is main content of integrated technology research.

In general, the data management information of product design and development process can be divided into three 
categories, namely, product information, process control information and organization structure information.

1) The product information is description of the product structure, design information and related documents. The part classified information include self-made part, universal part, out purchased part, assembly part, machining part. The management information include basic information (such as document name, number, path, version, status, type, etc.), BOM information (such as assembly number, assembly relation, construction checklist, etc.), as well as change orders.

2) The process control information mainly include requirements definition, technical requirements and application system output information, process information, manufacturing information, etc.

3) The organization structure information includes the description of working group, role, organizational structure and limits of authority of the staff in product development process.

\section{B. CAx integrated information organization}

Using object-oriented management mechanism, to establish a product structure information tree is an important means to effectively organize information. The data model of product development process is created by way of layers decomposition for products structure. Similar to a node tree, each node contains additional information associated attributes. The generic relation and aggregation relation between layer and layer are form. Finally, the product structure information tree is established on basis of the product structure tree. This structure provides a single source of product data, and lays a foundation for global data consistency and sharing. Figure 2 describes the product structure information tree.

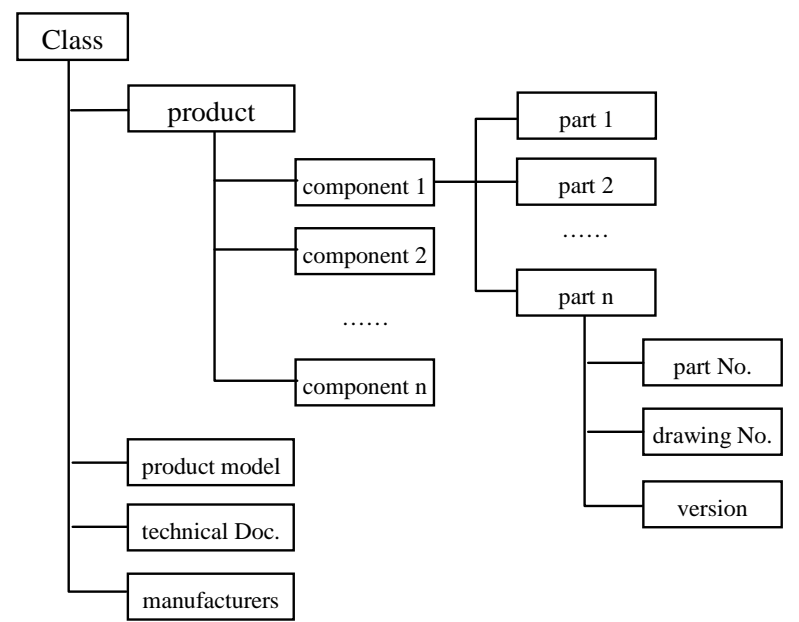

Figure 2. The product structure information tree

The product structure information tree is correspondingly reference to component parts independent exist in the database. There is only a storage instance of the component part in the database. As soon as this instance is modified, all structure referenced to the component part are linked to modify on the product structure information tree. This linkage modifications great retains real-time updates of the product structure tree, and guarantees integrity and consistency for related data of product structure information tree.
The principle to build product structure information tree is "reference". If a component part which need to be reference does not already exist, it should firstly be created, and then use one with a referential relationship. Therefore, it is necessary to organize corresponding assembly parts and component parts, and facilitate query. The method of building sub assembly folder and components folder can be adopt. The data organization form taking part as a unit, as shown in figure 3. For each component part, several different versions may co-exist, and constitute multiple instances of such object.

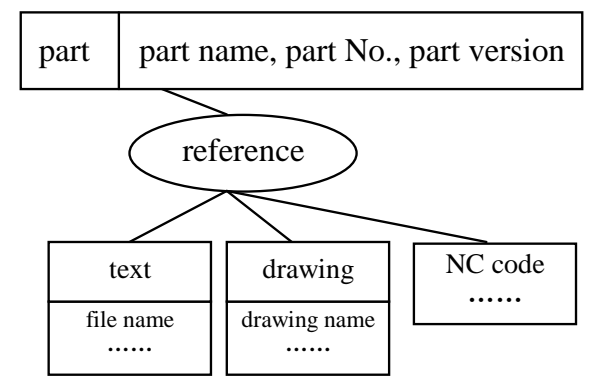

Figure 3. The reference model of parts and related attribute

In fact, in order to reduce duplication of drawing work and improve the parts reusability, same encoding component parts can be installed in additional multiple assembly parts. Therefore, the assembly relation between component parts is a many-to-many mesh structure. There are studies showing that the mesh structure can be transformed into a tree structure in the circumstances not to waste storage space.

\section{The DATA StRUCtURE OF INTEgRATED PRODUCT MODEL}

Whether product development or manufacturing process, the project is as the center. According to organization mode of the product structure, tasks configure are made. Therefore, how to build the integrated product model based on the relational database is particularly important. Based on the relational database with object-oriented layer, the object-oriented data structure is established, and then the object is mapped to tables in a relational database. Thus, information transfer between CAx systems can be carried out via the integrated platform, instead of directly to pass information between each other.

\section{A. UML object model}

According to different types of products, the data structure of product definition model will vary. In order to effectively manage the product data of integrated product development system, the object-oriented method is used to describe the product information. The product class, parts class, parts class, view class, working group classes and members' class are defined. With the hierarchical structure of class, the product information is expressed. The appropriate data structure is designed with the class diagrams of Unified Modeling Language (UML). The big class has its own defined properties and their attribute subclasses. The concrete structures, as shown in figure 4 . 


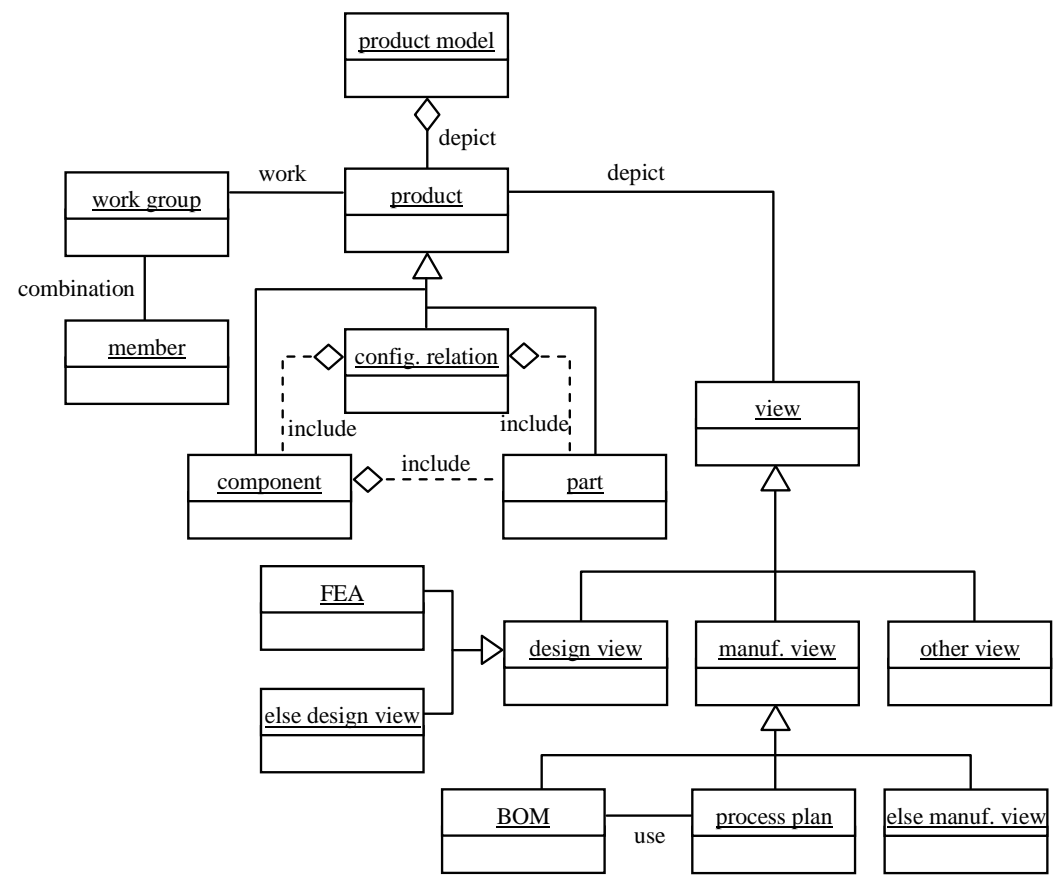

Figure 4. The data structures of product integration information

Through the product class, components class, parts class, the product information can be probably described. The view object class describes the view of information for different stages of product development and different people, such as design view, manufacturing view, assembling views, as well as other necessary views, and so on. It can be used to support different needs for product model at different stage of collaborative product development.

Object-oriented product data model provides a hierarchical data structure. The product classes, components class, parts class of the model are relative. Think alone of the components and parts, all of which are regard as a complete and specific product, and a different level product.

\section{B. Object mapping}

However, the relational database does not directly support object-oriented management model of product data integration, and it is still the mainstream of the current database. Therefore, it need be made to map object- oriented model to the relational data model. Using the comparison relationship, the components corresponding relationship for any complex product can be described. Database storage can use E-R semantic modeling approach to be described as follows:

$\mathrm{E}=$ \{component parts identification, technical parameter 1 , parameter $2, \ldots\}$

$\mathrm{R}=$ \{parent, child, child number $\}$

Hereinto, E- the relational mode of parts itself property. $\mathrm{R}$ - the relationship between the layers of product structure tree. If $\mathrm{R}$ has no parent or parent is its own, the part is the product. The content of $\mathrm{E}$ and $\mathrm{R}$ can be appropriately extended according to specific application. An instance is as shown in figure 5 .

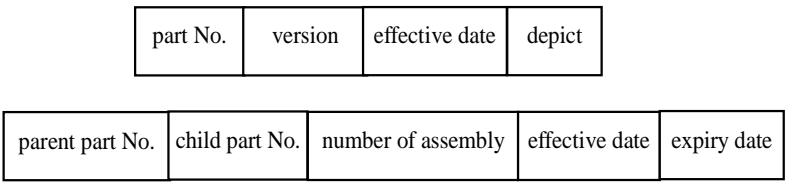

Figure 5. The product data structures define in database

The parent part and child part of product structure tree are associated by part number in the relational database. The part text, drawings, NC program are associated with the part by reference pointer.

New product development is an iterative and backtracking process, and is a heuristic forward process. The past design should be able to make reservations, to facilitate some requirements need to return to the past abandoned design for some reason. This structure is designed to support product design data going back. Using a reference principle, parts and components, components and products, parts and its different versions are associated with the part by reference pointer. If a design need be discarded, just to cut the corresponding reference relationship and the instance of design is still saved in the database. Thus, when this design need be reuse, the reference relationship is only rebuilt.

\section{KNOWLEdGe-BAsed PRoduct DeVELOPMENT INTEGRATED FRAMEWORK}

\section{A. Framework description}

The knowledge-based product development integrated system is based on product data management system and knowledge management system. Based on case-based reasoning and rule-based reasoning and interactive design for product development, the design knowledge base and product database is as core and the knowledge-based intelligent utility is integrated. Therefore, the knowledgebased product development integrated system includes the design knowledge management systems and product data management system, as shown in Figure 6. 


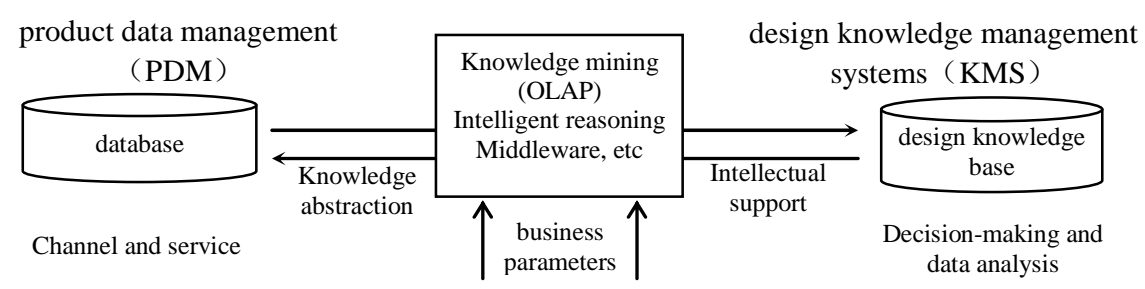

Figure 6. The form of knowledge-based product development integrated system

The product design knowledge management system (KMS) includes databases, knowledge analysis, design knowledge base management, design knowledge sharing tools, collaborative mechanisms, etc. The product data management system (PDM) includes engineering data management, document management, product information management, technology data management, product configuration management, workflow management, project management, etc. Both are organically combined. The knowledge-based product development integrated system provides a development environment in which software platform as the basis, application software system as the core and the support services (management, decision support, knowledge sharing) as the guarantee. It provides real-time information and real-time decision support, to realize fast, efficient, accurate intelligent management.

The knowledge-based product development integrated system collects lots of information about production by $\mathrm{CAD} / \mathrm{CAE} / \mathrm{CAP} / \mathrm{CAM}$ system. This information is handled by the knowledge management tools such as the knowledge database, knowledge mining, online analytical processing (OLAP) and intelligent reasoning systems, etc, and accurate and instant response is made by the decision support system. The data warehouse technology is the important foundation of intelligent integrated system. Through data warehouse, the system can retrieve and load raw data, and analyze and query information for managers. Knowledge Base itself can manage large amounts of data, and handle efficiently complex queries. Data analysis and query can be made with all kinds of advanced technology such as fuzzy query, multidimensional analysis, what-if analysis, etc. In addition, the system is also necessary to establish a security mechanism that gives different positions with different permissions, to obtain different degree information.

\section{B. Technical architecture}

The knowledge-based product development integrated system is not only to introduce design knowledge management system in traditional PDM, it is a unity of the PDM system and KMS, and is the organic combination of artificial intelligence technology and PDM system. PDM is the basis of product design integrated knowledge management, and knowledge management system provides advantageous guarantee for successful application of PDM. Through the CAD/CAE/CAM/CAPP /PDM system, the enterprise can get large amounts of information, and enhance application knowledge capacity. Through knowledge management system, the knowledge can be transmitted and exchanged, so that the employee's personal knowledge can be easily transformed into "enterprise knowledge" and be made sharing within the enterprise. PDM and KMS are closely linked to effectively manage the enterprise resources. The technical architecture of the knowledge-based product development integrated system, as shown in Figure 7.

$\mathrm{PDM}$ is the integration platform of CAD/CAE /CAPP/CAM system. KMS system consists of the database, data analysis, data mining, decision support, etc. It makes the foreground PDM information to filter, analyze, and store. The reasoning results backed to the system by inference machines, and form the background of the product development integration system.

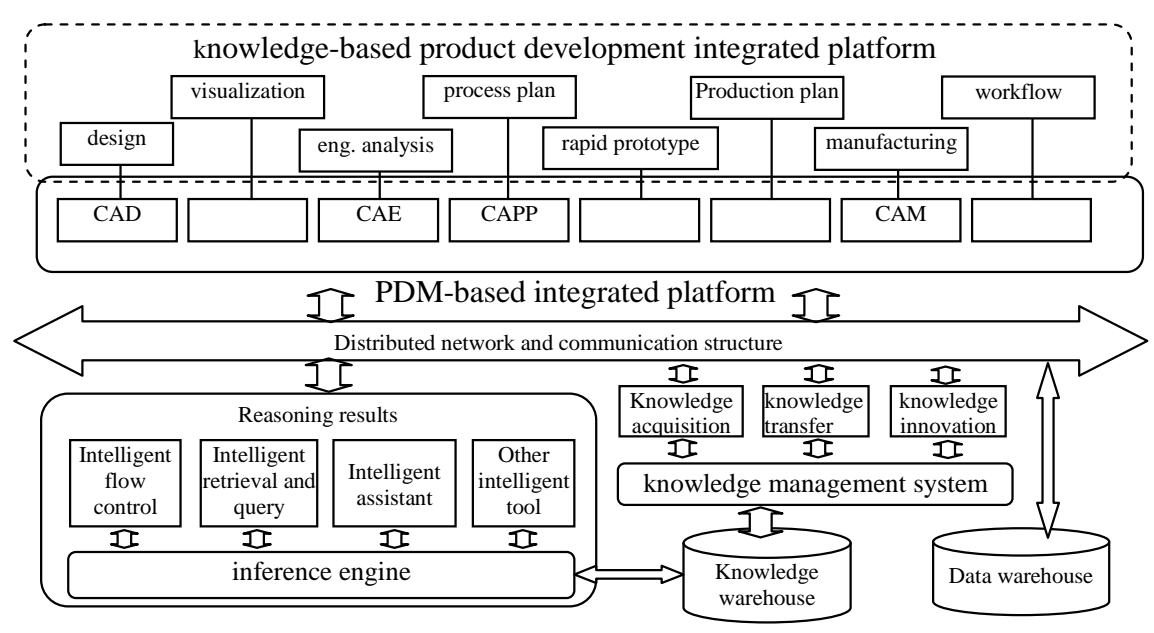

Figure 7. The technical architecture of knowledge-based product development integrated system 
Knowledge-based reasoning is the core modules of the technical architecture, including knowledge acquisition, knowledge base and inference engine. Knowledge acquisition modules analyze large amounts of information with advanced data mining algorithms to conclude the knowledge rules. Knowledge representation can be a production rule, frame or semantic network. Corresponding knowledge stored method is different along with different knowledge representation. According to the existing knowledge and conditions, reasoning machine is used to deduce meaningful results. Reasoning machine is the realization of reasoning strategy. It contains important search strategies and inference model.

\section{CONCLUSIONS}

In knowledge economy age, knowledge has become a key economic resource of the enterprise and to become even only source of competitive advantage. Knowledge management as the support of knowledge economic development and the means of knowledge innovation has become the attention focus of the government and enterprise. Based on the analysis on CAx integrated information, the paper study a data structure of integration product model based on the relational database. Then, a knowledge-based product development integrated framework based on the product data management system and the knowledge management system is puts forward. The enterprise build integrated product development environment based on knowledge, and help to improve product innovation capacity, shorten the product design cycle, and enhance the competitive capacity of enterprises.

\section{REFERENCES}

[1] P. Nicolas and A K. Samar, "A knowledge engineering method for new product development.” J. Dec. Sys., vol. 19, no. 1, pp. 117-133, 2009.

[2] C. Angelo, L. Robert, M. Alessandro and T. Giuseppe, "Enhancing product development through knowledge-based engineering (KBE)-A case study in the aerospace industry." $J$. Manu. Tech. Man., vol. 20, no. 8, pp. 1070-1083, 2009. http://dx.doi.org/10.1108/17410380910997218

[3] G. Ian, A. Abu Khari Bin, "The development of an online support tool for the teaching and learning of the IEEE standard 1500 for embedded core-based integrated circuits." Int. J. Online Eng., vol. 8, no. 4, pp. 42-49, 2012.

[4] K. Dimitris A., C. Ewart R. and C. Paul O, "Towards knowledgebased systems in clinical practice: Development of an integrated clinical information and knowledge management support system.” Com. Meth. Prog. Biom., vol. 72, no. 1, pp. 65-80, 2003.

[5] F. Ardeshir, L. Adam, H. Khaled and H. Heather, "Integrated knowledge-based geographic information system for determining optimal location of park-and-ride facilities.” J. Urban Plan. Dev., vol. 128, no. 1, pp. 18-41, 2002. http://dx.doi.org/10.1061/ (ASCE)0733-9488(2002)128:1(18)

[6] Paton. N.W., Goble. C.A. and Bechhofer. S, "Knowledge based information integration systems.” Info. Soft. Tech., vol. 42, no. 5, pp. 299-312, 2000. http://dx.doi.org/10.1016/S0950-5849(99) $\underline{00090-7}$

[7] T. Kevin C. and E G. Waleed, "An intelligent system based on concurrent engineering for innovative product design at the conceptual design stage.” Int. J. Adv. Manu. Tech., vol. 63, no. 5, pp. 421-447, 2012. http://dx.doi.org/10.1007/s00170-012-3932-7

[8] M. Vesna, E. Dragan, A. Dragan, et al., "Concurrent engineering based on virtual manufacturing.” Tehnicki Vjesnik, vol. 19, no. 4, pp. 885-892, 2012.

[9] D. Namchul and C. Gyoengseok, "A product data Management architecture for integrating hardware and software development." Computers in Industry, vol. 62, no. 8, pp. 854-863, 2011. http://dx.doi.org/10.1016/j.compind.2011.09.001

[10] S. J. Daniel, B. David and S. William E., "New product development performance and the interaction of cross-functional integration and knowledge management.” J. Prod. Inno. Man., vol. 22, no. 5, pp. 399-411, 2005. http://dx.doi.org/10.1111/ j.1540-5885.2005.00137.X

[11] W. Huang, Y. Wang, Q. Xie and Q. Ding, "Research on management of design knowledge based on ontology in the integrated product development.” China Mech. Eng., vol. 18, no. 21, pp. 2566-2569, 2007.

\section{AUTHORS}

Yongdang Chen is with College of Mechanical \& Electrical Engineering, Xi'an Polytechnic University, Xi’an, 710048 China (e-mail: chenyongd@163.com).

Zhiqiang Bao is with College of Mechanical \& Electrical Engineering, Xi'an Polytechnic University, Xi’an, 710048 China (e-mail: baozhiqiang214@qq.com).

Huijuan Ren is with College of Computer Science, Xi'an Polytechnic University, Xi'an, 710048 China (email: renhuij@126.com).

Huali Ma is with College of Mechanical \& Electrical Engineering, Xi'an Polytechnic University, Xi'an, 710048 China (e-mail: 690507282@qq.com).

Guangmei Liu is with College of Mechanical \& Electrical Engineering, Xi'an Polytechnic University, Xi’an, 710048 China (e-mail: 937850450@qq.com).

This work was supported by Science \& Technology Research Guidance Program Funded by China National Textile And Apparel Council (No.2011087), the Scientific Research Program Funded by Shaanxi Provincial Education Department (No.11JK1034), and Science \& Technology Research Program in Xi'an City (Program No.CXY11251). This article is an extended and modified version of a paper presented at the International Conference on Mechanical Engineering, Automation and Material Science (MEAMS2012), held 22-23 December 2012, Wuhan, China.Received 18 March 2013. Published as resubmitted by the authors 01 May 2013. 